\title{
RANCANG BANGUN AUGMENTED TOUR MUSEUM SANDI YOGYAKARTA SEBAGAI MEDIA INFORMASI PENGUNJUNG
}

\author{
Prita Haryani \\ Fakultas Teknologi Industri, Program Studi Teknik Informatika \\ Institut Sains dan Teknologi AKPRIND Yogyakarta \\ Email: pritaharyani@akprind.ac.id \\ Joko Triyono \\ Fakultas Teknologi Industri, Program Studi Teknik Informatika \\ Institut Sains dan Teknologi AKPRIND Yogyakarta \\ Email: jack@akprind.ac.id
}

\begin{abstract}
ABSTRAK
Museum Sandi yang berlokasi di J1. Faridan Muridan Noto No. 21, Kotabaru, Yogyakarta menampilkan berbagai koleksi persandian bersejarah dalam bentuk realia, replika, mesin, gambar, dan dokumen terkait persandian. Berdasarkan data yang diperoleh, media informasi yang digunakan dalam memperkenalkan informasi museum kepada masyarakat menggunakan brosur, katalog, dan media sosial (instagram dan twitter). Di dalam brosur dan katalog hanya memuat informasi mengenai koleksi persandian yang ada di museum, belum terdapat informasi mengenai tata letak ruang pamer dan alur kunjungan Museum Sandi. Berdasarkan fakta tersebut, pada penelitian ini dirancang Augmented Tour Museum Sandi untuk mempermudah pengunjung memperoleh informasi mengenai tata letak ruang pamer serta alur kunjungan di Museum Sandi. Model pengembangan yang digunakan pada penelitian ini adalah model waterfall. Berdasarkan hasil pengujian yang telah dilakukan, diperoleh kesimpulan bahwa perancangan Augmented Tour Museum Sandi dapat memberikan solusi terhadap masalah informasi tata letak ruang pamer dan alur kunjungan pada Museum Sandi. Augmented Tour Museum Sandi yang dirancang dapat memvisualisasikan objek ke dalam bentuk 3 dimensi yang bersifat real time, sehingga memungkinkan pengunjung untuk berinteraksi dengan cara yang intuitif dan menarik. Informasi yang ada pada Augmented Tour Museum Sandi juga bermanfaat dan sesuai dengan harapan pengunjung. Pengunjung juga bersedia merekomendasikan Augmented Tour Museum Sandi kepada calon pengunjung lain.
\end{abstract}

Kata kunci: augmented tour; media informasi; museum sandi; pengunjung; waterfall.

\begin{abstract}
The Sandi museum is located at Jl. Faridan Muridan Noto No. 21, Kotabaru, Yogyakarta, shows various collections of historical code in the form of realias, replicas, machines, pictures, and documents related to code. Based on the data obtained, the information media, that is used to introduced museum information to community, uses brochures, catalogs, and social media (instagram and twitter). In the brochures and catalogs. they only consist of information about existing code collection in the museum, there has not been information about the layout of exhibition room and visting flow at Sandi Museum yet. Based on that fact, in this research, it is designed Augmented Tour of Sandi Museum in order to make it easier for the visitors to get information about the layout of exhibition room as well as visiting flow at Sandi museum. The development model used in this research is waterfall model. Based on the testing result that has been done, it is obtained conclussion that the designing of Augmented Tour at Code Museum can give solution towards the information problem of the layout of exhibition room and visiting flow at Sandi Museum. Augmented Tour at Sandi Museum, which is designed, is able to visualize the objects in the shape of 3 Dimensions that is real time characterized, therefore, it enables the visitors to interact in an intuitive and interesting way. The information in Augmented Tour of Sandi Museum is also useful and appropriate with the visitors' expectation. The visitors are also ready to recommend Augmented Tour of Sandi Museum to other visitors.
\end{abstract}

Keywords: augmented tour; information media; sandi museum; visitors; waterfall. 


\section{PENDAHULUAN}

Sesuai dengan Peraturan Pemerintah RI No. 19 Tahun 1995, museum merupakan tempat penyimpanan, perawatan, pengamanan, dan pemanfaatan benda-benda bukti materiil hasil budaya manusia serta alam dan lingkungannya guna menunjang upaya perlindungan dan pelestarian kekayaan budaya bangsa. Salah satu museum yang menyimpan benda-benda bersejarah sebagai sumber informasi kekayaan budaya bangsa adalah Museum Sandi.

Museum yang berlokasi di Jl. Faridan Muridan Noto No. 21, Kotabaru, Yogyakarta, menampilkan berbagai koleksi persandian bersejarah dalam bentuk realia, replika, mesin, gambar, dan dokumen terkait persandian. Museum Sandi menempati gedung cagar budaya yang dahulu digunakan sebagai kantor Kementrian Luar Negri pada tanggal 29 Januari 2014. Area Museum Sandi cukup luas dan terdiri dari dua lantai. Terdapat 12 ruang pamer koleksi persandian dan 10 ruangan yang menjadi fasilitas Museum Sandi bagi pengunjung.

Berdasarkan data yang diperoleh, media informasi yang digunakan dalam memperkenalkan informasi museum kepada masyarakat menggunakan brosur, katalog, dan media sosial (instagram dan twitter). Di dalam brosur dan katalog hanya memuat informasi mengenai koleksi persandian yang ada di museum, belum terdapat informasi mengenai tata letak ruang pamer dan alur kunjungan Museum Sandi. Sedangkan di dalam media sosial (instagram dan twitter) lebih banyak menampilkan informasi mengenai kegiatan yang sering dilakukan di Museum Sandi. Berdasarkan hasil wawancara dengan pengunjung Museum Sandi diperoleh kesimpulan bahwa pengunjung juga mengalami kesulitan mencari tata letak ruang pamer sesuai dengan koleksi persandian yang ada di brosur dan katalog karena belum adanya informasi mengenai alur kunjungan tersebut.

Untuk mengatasi permasalahan informasi mengenai tataletak ruang pamer koleksi persandian dan alur kunjungan Museum Sandi diperlukan sebuah media informasi yang tepat bagi pengunjung untuk mendapatkan informasi tersebut. Pada penelitian ini dirancang sebuah media informasi dengan teknologi Augmented Reality. AR memberikan gambaran kepada pengguna tentang penggabungan dunia nyata dengan dunia maya dilihat dari tempat yang sama [1]. Teknologi ini memiliki kelebihan yaitu memiliki karakteristik yang bersifat interaktif menurut waktu nyata (real time) dan berbentuk 3D[1]. Diagram ilustrasi AR dapat dilihat pada Gambar 1, dimana AR merupakan penggabungan dunia nyata dan dunia maya.

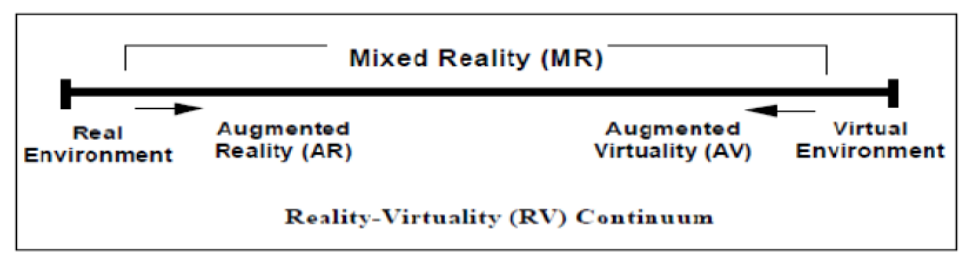

Gambar 1. Diagram Ilustrasi Augmented Reality [2]

Teknologi AR dapat digunakan sebagai media untuk memperkenalkan benda cagar budaya kepada masyarakat, salah satunya yaitu museum [3]. Karakteristik teknologi AR yang bersifat interaktif dapat dijadikan sebagai media oleh pihak penyelenggara museum untuk menarik minat pengunjung. Pengunjung dapat menvisualisasikan objek atau benda bersejarah ke dalam dimensi 3D yang bersifat real time. Pengenalan museum berbasis AR ini memungkinkan pengunjung untuk berinteraksi dengan konten dengan cara yang intuitif dan menarik [4]. Teknologi Augmented Reality juga diimplementasikan pada buku panduan wisata. Aplikasi AR ini akan menunjukkan video dan animasi 3D ke pengguna tentang rute untuk melintasi kota yang menampilkan semua bangunan bersejarah. Setiap gambar memiliki kode QR yang memberikan akses ke informasi dan pengguna memindai kode QR dengan smartphonenya [5]. Implementasi AR lainnya dilakukan pada proses pembelajaran sejarah dengan teknik MARS (MultiTouch Augmented Reality System). Dengan teknik MARS (Multi-Touch Augmented Reality System), terdapat dua buah layar yang digunakan sebagai media pembelajaran siswa. Layar pertama menampilkan peta informasi secara kontekstual dan layar kedua menampilkan informasi mengenai peristiwa bersejarah secara 3D pada lokasi tersebut [6].

Berdasarkan penjelasan mengenai keunggulan pemanfaatan teknologi AR pada media informasi pengenalan museum, maka pada penelitian ini akan dirancang sebuah Augmented Tour Museum Sandi. Augmented Tour Museum Sandi ini akan menampilkan tata letak ruang pamer dan alur kunjungan pada Museum Sandi dalam bentuk 3 dimensi. Pada Augmented Tour Museum Sandi akan diberi fitur zoom dan rotate agar pengunjung dapat memperbesar dan memutar tata letak Museum Sandi yang disajikan dalam bentuk 3 dimensi. 


\section{METODOLOGI PENELITIAN}

Pendekatan penelitian yang digunakan pada penelitian ini adalah pendekatan penelitian pengembangan (research and development) dengan model pengembangan waterfall. Prosedur pengembangan dari model waterfall terdiri dari lima tahap yaitu [7] :

a. Tahap pertama dari model pengembangan waterfall adalah melakukan analisis dengan mengumpulkan data mengenai item kebutuhan dan struktur aplikasi perangkat lunak yang akan dibangun.

b. Tahap kedua adalah merancang desain aplikasi yang merupakan terjemahan dari item kebutuhan dan struktur aplikasi.

c. Implementasi, Tahap ketiga adalah tahap pembuatan aplikasi Augmented Reality. Software pendukung yang digunakan yaitu Unity3D versi 20172.0 dan Vuforia SDK

d. Tahap keempat yaitu tahap pengujian dimana verifikasi dan validasi aplikasi perangkat lunak dilakukan. Pengujian dilakukan dengan menggunakan pengujian blackbox testing, whitebox testing, dan pengujian oleh pengguna.

e. Tahap terakhir dari model waterfall ini adalah tahap pemeliharaan. Pada tahap pemeliharaan proses instalasi produk dan pemeliharaan dilakukan. Pemeliharaan dilakukan dengan melakukan pembaharuan pada aspek sistem dan informasi sehingga keberlanjutan siklus hidup dari aplikasi bisa berjalan dengan baik.

\section{HASIL DAN PEMBAHASAN}

Pembahasan dari tahap penelitian yang dilakukan adalah sebagai berikut:

\subsection{Analisis}

Pada pembuatan Augmented Tour Museum Sandi, informasi yang dibutuhkan meliputi tata letak ruangan dan alur kunjungan Museum Sandi pada lantai 1 dan lantai 2. Berikut ini adalah tata letak ruangan dan alur kunjungan Museum Sandi pada lantai 1 dan lantai 2.

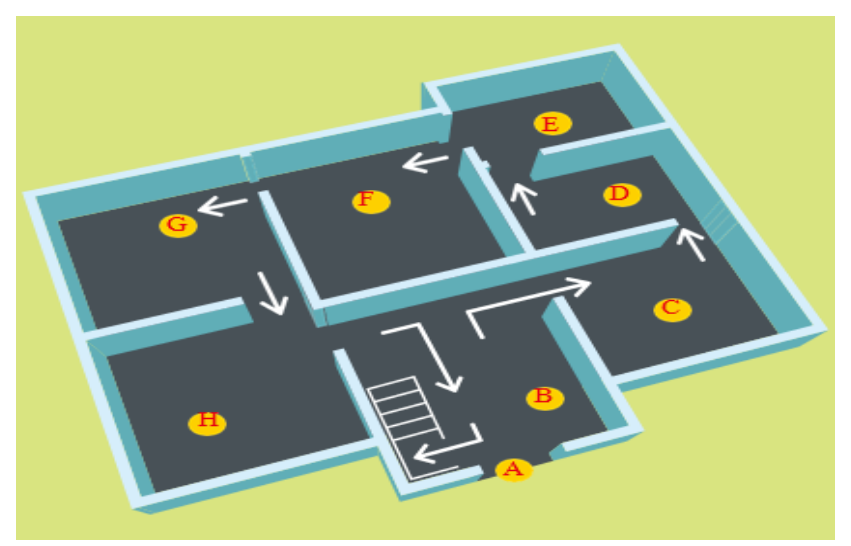

\section{Gambar 2. Alur Kunjungan Lantai 1}

Pada alur kunjungan lantai 1 terdapat 8 ruang pamer yang bisa dikunjungi yaitu Pintu Masuk Museum Sandi (A), Kiosk Pengunjung (B), Ruang Intro (C), Ruang Agresi Militer 1 (D), Ruang Agresi Militer II (E), Ruang Maket Dukuh (F), Ruang Merdeka (G), dan Ruang Nusantara (H). Pada masingmasing ruangan terdapat mesin-mesin persandian yang menjadi obyek pameran dari Museum Sandi. Sedangkan pada alur kunjungan lantai 2 terdapat 4 ruang pamer yang bisa dikunjungi yaitu Tangga Masuk Lantai 2 (I), Ruang Tokoh (J), Ruang Sandi Global (K), dan Ruang Edukasi (L). Di lantai 2 terdapat ruang edukasi yang didalamnya terdapat game persandian sederhana yang dapat dimainkan oleh pengunjung. Alur kunjungan pada lantai 2 dapat dilihat pada gambar 3. 


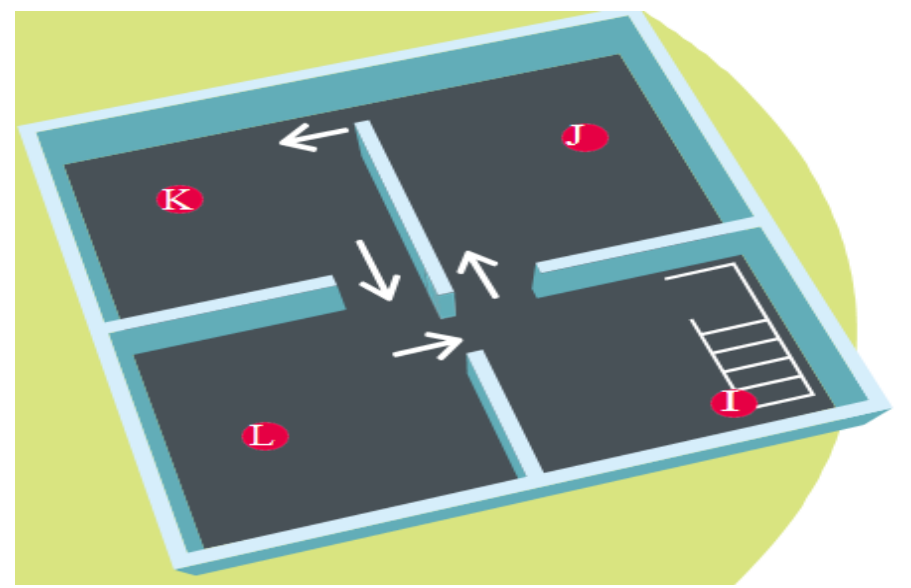

Gambar 3. Alur Kunjungan Lantai 2

\subsection{Desain}

Desain yang dibuat berupa sketsa alur kunjungan pada lantai 1 dan lantai 2 dalam bentuk 3 dimensi. Untuk menggambar sketsa 3 dimensi alur kunjungan pada lantai 1 dan lantai 2, digunakan bantuan software Google SketchUp. Berikut adalah tampilan pembuatan sketsa 3 dimensi alur kunjungan lantai 1 dan lantai 2.

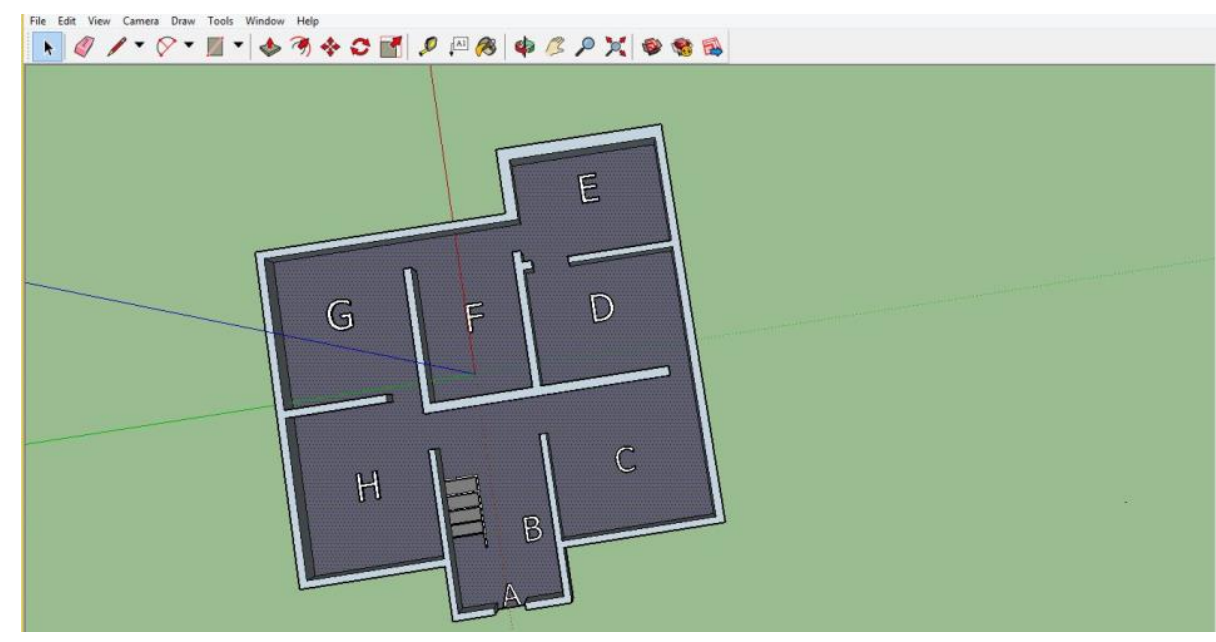

Gambar 4. Sketsa Alur Kunjungan Lantai 1 Menggunakan Google SketchUp

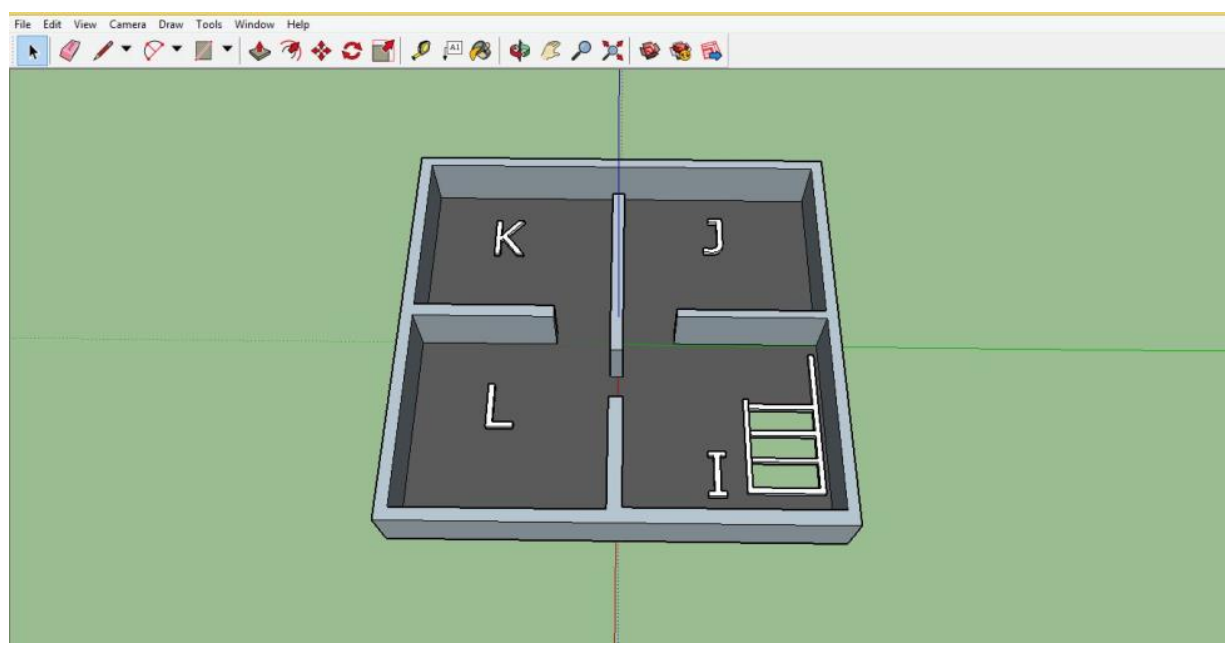

Gambar 5. Sketsa Alur Kunjungan Lantai 2 Menggunakan Google SketchUp 


\subsection{Implementasi}

Setelah desain dibuat, tahap selanjutnya yaitu membuat atau mengembangkan aplikasi perangkat lunak yaitu aplikasi Augmented Tour Museum Sandi. Pembuatan Augmented Tour Museum Sandi menggunakan software Unity3D versi 20172.0 dan Vuforia SDK. Untuk membuat database dari gambar marker yang akan digunakan bisa melalui website vuforia dengan membuat accout terlebih dahulu pada website tersebut. Berikut ini adalah gambar diagram alir Augmented Tour Museum Sandi dalam penggunaan marker AR.

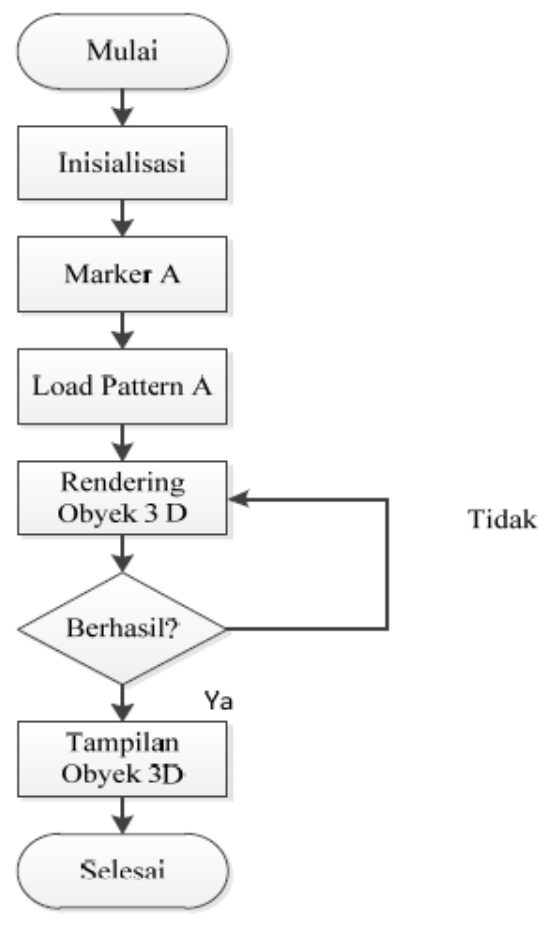

\section{Gambar 6. Diagram Alir Augmented Tour Museum Sandi}

Setelah selesai proses pembuatan marker dan rendering obyek ruang pamer serta alur kunjungan 3 dimensi berhasil, maka ketika marker disorot dengan kamera akan tampil obyek 3 dimensi tersebut. Berikut adalah gambar ketika marker berhasil menampilkan gambar 3 dimensi.

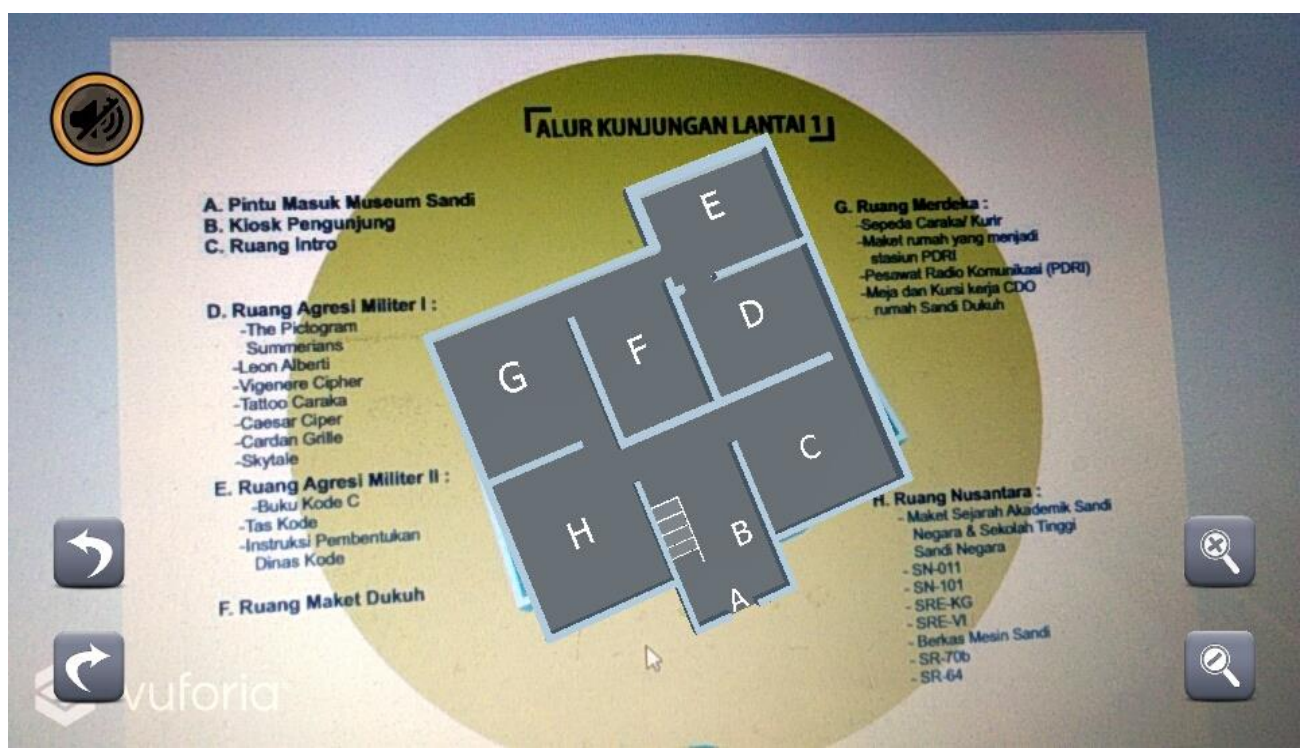

Gambar 7. Tampilan Gambar 3 Dimensi Pada Lantai 1 


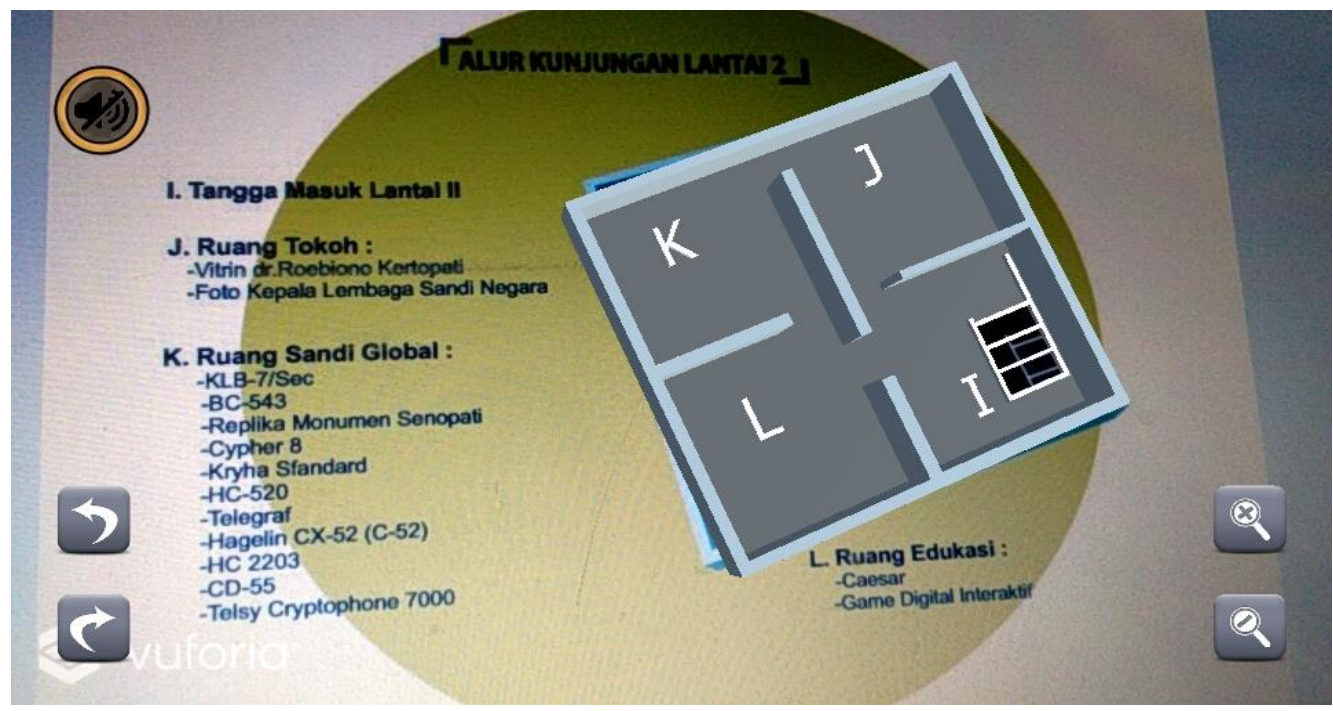

Gambar 8. Tampilan Gambar 3 Dimensi Pada Lantai 2

Pada gambar 7, ketika marker disorot maka akan menampilkan gambar 3 dimensi ruang pamer koleksi persandian dan alur kunjungan pada lantai 1 dan pada gambar 8 ketika marker di sorot maka akan menampilkan gambar 3 dimensi ruang pamer koleksi persandian dan alur kunjungan pada lantai 2. Pada aplikasi tersebut juga ditambahkan fitur rotate dan zoom untuk mempermudah pengunjung ketika ingin melihat gambar 3 dimensi tersebut lebih detail. Sedangkan pada gambar marker ditambahkan keterangan mengenai benda koleksi persandian yang ada pada setiap ruangan sehingga pengunjung dapat dengan mudah menemukan letak benda koleksi persandian pada setiap ruang pamer.

\subsection{Pengujian}

Pengujian Augmented Tour Museum Sandi dilakukan dengan menggunakan pengujian blackbox testing, whitebox testing, dan pengujian oleh pengguna. Pengujian blackbox testing dilakukan dengan tujuan untuk menguji kebenaran proses aplikasi Augmented Tour Museum Sandi. Dari hasil pengujian diperoleh hasil bahwa semua proses aplikasi Augmented Tour Museum Sandi berjalan dengan baik, dimulai dari saat pertama kali aplikasi dijalankan sampai dengan selesai keluar dari aplikasi berfungsi dengan baik. Begitu pula denga fitur rotate dan zoom pada gambar 3 dimensi pada lantai 1 dan lantai 2 juga sudah berfungsi dengan baik. Pengujian juga dilakukan dengan menggunakan 3 smartphone yang memiliki spesifikasi berbeda. Dari hasil pengujian yang dilakukan, aplikasi Augmented Tour Museum Sandi dapat berjalan dengan baik pada ketiga smartphone tersebut.

Tabel 1. Spesifikasi smartphone untuk pengujian blackbox testing

\begin{tabular}{|c|c|c|c|c|}
\hline Spesifikasi & Smartphone A & Smartphone B & & Smartphone C \\
\hline OS & $\begin{array}{l}\text { Android OS, } \\
\text { (Marshmallow) }\end{array}$ & Android 7.1 (Nougat) & & Android 8.0 (Oreo) \\
\hline CPU & $\begin{array}{l}\text { Quad-core } 1.4 \mathrm{GHz} \text { Cortex- } \\
\text { A53 }\end{array}$ & $\begin{array}{ll}\text { Quad-core } & 1.4 \\
\text { Cortex-A53 } & \end{array}$ & $\mathrm{GHz}$ & $\begin{array}{l}\text { Quad-core } 1.4 \mathrm{GHz} \\
\text { Cortex-A53 }\end{array}$ \\
\hline Display & 5.0 inches, 540 x 960 pixels & $\begin{array}{l}5.0 \text { inches, } 540 \mathrm{x} \\
\text { pixels }\end{array}$ & 960 & 5.5 inches, $83.4 \mathrm{~cm} 2$ \\
\hline Memory & $8 \mathrm{~GB}, 1.5 \mathrm{~GB}$ RAM & $16 \mathrm{~GB}, 1.5 \mathrm{~GB}$ RAM & & 8 GB, 2 GB RAM \\
\hline
\end{tabular}

Pengujian whitebox testing dilakukan untuk mengetahui cara kerja suatu perangkat lunak secara internal. Dari hasil pengujian diperoleh semua fungsi dari source code berjalan sesuai dengan fungsinya dan berjalan dengan baik dan benar.

Pengujian yang terakhir dilakukan oleh pengguna. Uji lapangan dilakukan terhadap 30 orang pegunjung Museum Sandi. Pengunjung mengisi kuesioner tentang penilaian aplikasi Augmented Tour Museum Sandi. Hasil dari jawaban pertanyaan kuesioner kemudian diklasifikasikan berdasarkan tabel 2 berikut untuk mengetahui kualitas berdasarkan hasil prosentase yang diperoleh. 
Tabel 2. Klasifikasi kualitas berdasarkan persentase [8]

\begin{tabular}{cc}
\hline Persentase & Katagori \\
\hline $80 \%-100 \%$ & Sangat Tinggi \\
$60 \%-79 \%$ & Tinggi \\
$40 \%-59 \%$ & Cukup \\
$20 \%-39 \%$ & Rendah \\
$<20 \%$ & Sangat Rendah \\
\hline
\end{tabular}

Tabel 3. Data hasil kuesioner pengunjung

\begin{tabular}{clc}
\hline No & \multicolumn{1}{c}{ Pertanyaan } & Hasil (\%) \\
\hline 1. & $\begin{array}{l}\text { Apakah pengunjung mengalami permasalahan informasi mengenai tata letak } \\
\text { ruang pamer dan alur kunjungan pada Museum Sandi? }\end{array}$ & $100 \%$ \\
2. & $\begin{array}{l}\text { Apakah brosur dan katalog sudah memberikan informasi mengenai tata letak } \\
\text { ruang pamer dan alur kunjungan pada Museum Sandi? }\end{array}$ & $6.67 \%$ \\
3. $\quad \begin{array}{l}\text { Apakah pengunjung sudah mengetahui media informasi museum berbasis } \\
\text { augmented reality? }\end{array}$ & $33,33 \%$ \\
4. $\quad \begin{array}{l}\text { Apakah Augmented Tour Museum Sandi yang dirancang sudah sesuai dengan } \\
\text { harapan pengunjung? }\end{array}$ & $83,33 \%$ \\
5. $\quad \begin{array}{l}\text { Apakah informasi yang ada pada Augmented Tour Museum Sandi bermanfaat } \\
\text { untuk pegunjung? }\end{array}$ & $93,33 \%$ \\
6. $\quad \begin{array}{l}\text { Apakah pengunjung akan merekomendasikan Augmented Tour Museum Sandi } \\
\text { kepada calon pengunjung lain? }\end{array}$ & $76,67 \%$ \\
\hline
\end{tabular}

Berdasarkan hasil pengujian melalui kuesioner pada tabel 3, diperoleh hasil bahwa Augmented Tour Museum Sandi yang dirancang sudah sesuai dengan harapan pengunjung, informasi yang ada pada Augmented Tour Museum Sandi bermanfaat untuk pegunjung dan pengunjung akan merekomendasikan Augmented Tour Museum Sandi kepada calon pengunjung lain.

\subsection{Pemeliharaan}

Tahap terakhir dari model waterfall ini adalah tahap pemeliharaan. Proses instalasi produk dan pemeliharaan dilakukan dalam tahap ini. Pemeliharaan dilakukan dengan melakukan pembaharuan pada aspek sistem dan informasi.Aplikasi Augmented Tour Museum Sandi diharapkan dapat diimplementasikan di Museum Sandi dan diinstal dalam bentuk AR desktop maupun AR mobile.

\section{KESIMPULAN}

Berdasarkan hasil pengujian yang telah dilakukan, diperoleh kesimpulan bahwa perancangan Augmented Tour Museum Sandi dapat memberikan solusi terhadap masalah informasi tata letak ruang pamer dan alur kunjungan pada Museum Sandi. Augmented Tour Museum Sandi yang dirancang dapat memvisualisasikan objek ke dalam bentuk 3 dimensi yang bersifat real time, sehingga memungkinkan pengunjung untuk berinteraksi dengan cara yang intuitif dan menarik. Informasi yang ada pada Augmented Tour Museum Sandi juga bermanfaat dan sesuai dengan harapan pengunjung.

\section{UCAPAN TERIMA KASIH}

Terimakasih peniliti persembahkan kepada Kementrian Riset dan Pendidikan Tinggi yang telah membiayai penelitian ini dalam skema Penelitian Dosen Pemula pendanaan tahun 2018. Semoga penelitian dilakukan dapat memberikan manfaat bagi berbagai pihak.

\section{DAFTAR PUSTAKA}

[1] F. Manuri and A. Sanna, “A Survey on Applications of Augmented Reality,” vol. 5, no. 1, p. 10, 2016.

[2] R. Azuma, Y. Baillot, R. Behringer, S. Feiner, S. Julier, and B. MacIntyre, "Recent advances in augmented reality," IEEE Comput. Graph. Appl., vol. 21, no. 6, pp. 34-47, Dec. 2001.

[3] P. Haryani and J. Triyono, "AUGMENTED REALITY (AR) SEBAGAI TEKNOLOGI INTERAKTIF DALAM PENGENALAN BENDA CAGAR BUDAYA KEPADA 
MASYARAKAT," Simetris J. Tek. Mesin Elektro Dan Ilmu Komput., vol. 8, no. 2, p. 807, Nov. 2017.

[4] R. Wojciechowski, K. Walczak, M. White, and W. Cellary, "Building Virtual and Augmented Reality museum exhibitions," in Proceedings of the ninth international conference on $3 D$ Web technology - Web3D '04, Monterey, California, 2004, p. 135.

[5] E. R. Fino, J. Martín-Gutiérrez, M. D. M. Fernández, and E. A. Davara, "Interactive Tourist Guide: Connecting Web 2.0, Augmented Reality and QR Codes," Procedia Comput. Sci., vol. 25, pp. 338344, 2013.

[6] M. Novotný, J. Lacko, and M. Samuelčík, “Applications of Multi-touch Augmented Reality System in Education and Presentation of Virtual Heritage," Procedia Comput. Sci., vol. 25, pp. 231-235, 2013.

[7] Y. Bassil, "A Simulation Model for the Waterfall Software Development Life Cycle,” Int. J. Eng., vol. 2, no. 5, p. 7, 2012.

[8] S. Arikunto, Dasar-Dasar Evaluasi Pendidikan, 2nd ed. Jakarta: Bumi Aksara, 2012. 